\title{
A final word from outgoing Student editor, Sophia Antoniou
}

It is with immense gratitude that I sit to write this final editorial to observe the end of my post as Student Editor. The past two years have been unlike any others. Within my role as editor, I was fortunate enough to attend numerous dental events such as the Mouth Cancer Action Month launch, the presidential members committee meeting and the Slow Dentistry press event, all of which took place in person (as usual) up until 2020. Upon reflection, I never envisioned I would miss dental conferences as dearly as I do, given the online replacements that are devoid of the warmth of human company.

The dental profession has arguably faced one of the most challenging times in its history and I am proud to be part of the tenacious resilience that prevails after the battle of COVID-19 and its ensuing challenges. How has the dental workforce coped? Communication of one's battles, be they physical, mental or social, has empowered us to overcome our trials. Within dental school, the unity that adversity has brought, microcosmically reflects the wider reactions within NHS, mixed and private practices around the UK.

An exemplar army of dental students have undergone extensive training online and in person, to become equipped to perpetuate the enormous task of vaccinating Britain. Dentists have worked diligently to ensure patients are kept safe from airborne infections but also still receive a high standard of care. Clinicians have been simultaneously protecting themselves and other staff members by sharing the latest guidance, which is unceasingly adapting to our current situation as we speak. Alongside bearing the heavier financial burden of attaining enough PPE and new PPE that was not general practice to wear before. Even the upper echelons of the dental world have been left infuriatingly hampered at times by our current limitations.

\section{So, what now? Perhaps, we shall} continue to wear masks on public transport for decades to come. Perhaps, we shall instinctively socially distance ourselves from the person in front of us in the line. Perhaps, however, Zoom will eventually fade into the background along with these routines. As students, we are likely to bear lasting impacts, branded with COVID-19 for the rest of our working career. The new era of students and following generations will perhaps be abstractly musing about the cohort that trained amidst COVID19. An inconceivable concept, akin to war stories one learns about in history lessons, yet (hopefully) never experiences oneself. Technology has been forced to expand to keep up with the exponential demand that several lockdowns have requested, the growth of such potential has erupted now more than ever. It is exciting to witness these advances facilitating better healthcare in the form of; mass production of crucial vaccines, methods of delivering fluoride via our water supply, restorative optical mimicry, bioregenerative dentifrices and many more.

It is a truth universally acknowledged, that difficult journeys lead to beautiful destinations. This beautiful destination is in sight. I wish all of you the best of luck in your dental journeys and sending strength to all of the current final years, who have faced a tumultuous finale to their undergraduate training. Best of luck to all students about to sit final exams, as the testing spring season is among us once more.

This editorial position has opened many doors within my own personal journey. Something which has unlocked joy and growth has been seizing beneficial opportunities with vigour. With special thanks to David Westgarth, without whom my $B D J$ editorial journey would not have come into fruition.

Sophia Antoniou

https://doi.org/10.1038/s41406-021-0219-1

\section{SAFETY NET DELIVERED FOR DENTAL STUDENTS AS 2021 GRADUATION DEFERRED}

The British Dental Association Scotland has welcomed action from the Scottish Government in response to its call to support dental undergraduates who face having to repeat a year owing to COVID-19 disruption.

A bursary of up to $£ 6,750$ will now be offered to students at Aberdeen, Dundee and Glasgow Dental Schools that all moved to defer graduation given the limitations on clinical contact in the last year.

The BDA issued an open letter to Cabinet Secretary for Health and Sport Jeane Freeman, and Deputy First Minister and Cabinet Secretary for Education and Skills John Swinney on 2 February, calling for necessary action to prevent the next generation of dentists being saddled with unmanageable debt.

Scottish dental students can already expect to graduate with over $£ 34,000$ debt. An additional year of study without a bursary would have pushed levels to over $£ 40,000$.

The Scottish Government has also confirmed it will continue to support trainers and trainees, based in NHS practices across Scotland.

The BDA has renewed its call on the Scottish Government to provide additional funding to dental schools to mitigate the financial losses associated with the announcement.

David McColl, Chair, British Dental Association's Scottish Dental Practice Committee said: 'This is the leadership we've needed from the Scottish Government.

'No one wanted graduations to be deferred, but now the next generation of dentists have real certainty, support and protection from what would have been eyewatering levels of debt.

'It's inevitable that COVID-19 will widen oral health inequalities that have long blighted Scotland. We can draw some comfort that Ministers have helped secure the pipeline of new talent we'll need to meet these challenges.' 